\title{
E-banking and Monitoring as a Winning Strategy for Banks in a Hyper Competitive Environment Through Customer Satisfaction, in Kampala Uganda
}

\author{
Sazir Nsubuga Mayanja \\ School of Post Graduate Studies, University of Kigali, Kigali, Rwanda \\ Email address: \\ saznsumay@gmail.com \\ To cite this article: \\ Sazir Nsubuga Mayanja. E-banking and Monitoring as a Winning Strategy for Banks in a Hyper Competitive Environment Through \\ Customer Satisfaction, in Kampala Uganda. Science Journal of Business and Management. Special Issue: Business Policy\& Strategic \\ Management. Vol. 8, No. 2, 2020, pp. 64-73. doi: 10.11648/j.sjbm.20200802.13
}

Received: October 1, 2019 Accepted: October 22, 2019; Published: May 18, 2020

\begin{abstract}
The purpose of the study was to examine the effect of e-transaction monitoring on customer satisfaction, as a strategy in a hyper competitive environment, with Stanbic Bank Uganda Limited as the case study. The study involved 5 managers, 10 Middle Level staff involved in E-banking operations, 5 Head office (Stanbic) E-banking operative staff, 8 Customer relationship officers attending walk-in-customers and 63 Customers of Stanbic Bank. A cross-sectional approach, involving collecting data at once from employees and customers was adopted. A combination of quantitative and qualitative data analysis techniques was employed in this study. Quantitative data analysis techniques involved the use of descriptive statistics such as frequencies and percentages to summarize responses on issues of E-banking and customer satisfaction while the Pearson's correlation coefficient was used to establish the relationship between dimensions of E-banking and customer satisfaction as specified in the study objectives. Findings from descriptive statistics indicated that on average the respondents agreed that there are some e-transaction factors that do affect customer satisfaction which include; quick checking of account balances, easy access of account history, increased efficiency in account management and customer touch points which are user friendly. Further findings indicated that there was a weak statistically significant positive relationship between e-transaction and customer satisfaction. The appropriate degree of automation will vary from institution to institution mainly dependent on the scale, nature and complexity of the bank's business. Further research is recommended on the likely negative externalities of the adoption of information and communication technology in the financial services sector.
\end{abstract}

Keywords: Electronic, Customer Satisfaction, E-banking, Monitoring, Data, Banks, Strategy

\section{Introduction}

Customer satisfaction is a collection of outcomes of perception, evaluation and psychological reactions to the consumption experience with a product or service. This implies that customer satisfaction is a result of a cognitive and affective evaluation where some comparison standard is compared to the actually perceived performance [1]. During the 1980s programmers working on banking data bases came up with ideas for online banking transactions, and over time, Internet banking as a concept and in practice has been simultaneously evolving with the development of the World Wide Web and creative marketing in other sectors, such as online shopping, which promoted the use of credit cards through Internet [2]. Coincidentally in banking, technologies such as Electronic Funds Transfer at Point of Banking (EFTOPOB), Electronic Funds Transfer at Point of Living (EFTOPOL) and Electronic Funds Transfer at Point of Shopping (EFTOPOS) evolved. Many banking organisations have continued to perfect the skills of data warehousing and mining. The developments of these databases were widely used during the developments of ATMs. Electronic Banking (E-banking) services improved fast in the early 1990s when credit card, Automated Teller Machines (ATMs), and telephone banking services were the three 
major channels of service delivery.

\section{Literature Review}

Research carried out on e-banking in Saudi Arabia confirmed that through effective communication using reports and notices throughout the day about account operations, as well as ensuring the speed of electronic applications, customers are satisfied. Nonetheless, while ebanking has paid considerable attention to the confidentiality of customers' personal information, in addition to the confidentiality and privacy of electronic services, it has ignored the issue of customer awareness of the importance of confidentiality and privacy of their personal data [3]. In great contrast with the case of the traditional monthly or quarterly "bank statements", bouncing a cheque (accidentally) is a thing of the past. With internet banking customers can monitor their account (s) online any time, day or night. This has been made possible through use of Software programs such as Microsoft Money or Quicken; which make it is easy to reconcile an account with just a few mouse clicks. This way the customer easily and conveniently captures the data online, so as to accurately budget and track the deposits and withdrawals from their account. Internet bank may even allow you to view copies of the cheques you have written each month [4]. Similar conclusions have been arrived at by other researchers. Customers are attracted to e-banking because of, among others, providing services anywhere and anytime, 24-hour availability, no queues, low cost service and speed of provided services. It enables users to choose their service provider if their demands are not met by another, as a result of low switching costs. Low responsiveness rates put a bank at risk of losing the existing customers. As a result, providing quality services is a guarantee to meet the needs of users, as well as their retention [5]. However, the technology which has enabled bank customers to access their accounts conveniently and with ease, is double-edged. It has also enabled hackers and other criminals defraud banks and customers. In a survey by KPMG over half of respondents globally experienced increases in both external fraud total value and volume. Increasingly, between 2015 and 2018 fraud typologies included identity theft and account takeover, cyber-attack, card not present fraud and authorized push payments scams. Undaunted and fortunately, banks are heavily and successfully investing in new technologies, including machine learning real time fraud alerts, voice, facial \& fingerprint recognition (biometrics) and profiling how customers interact with their device and internet banking (behavioural biometrics) for use in fraud prevention [6]. In a study on security and fraud issues of e-banking results indicated that the "transaction monitoring" model was the most effective, while "virtual keyboards", "Browser Protection" and "Device Identification" were the worst [7]. The 24/7/365 ability to view an account, has with the use of the technologies above, enabled banks and customers, to keep the number of successful frauds to occur with far less frequency and to involve lesser quantum of loss than would otherwise have been. Customers and banks commence on correcting the problem almost real-time than would have been the case in traditional banking, where customers would have to wait a month or so to receive an account statement by post to even know what is happening. If a bank's performance is perceived by the customers to be less than expected, they will have been dissatisfied. On the other hand, if the perceived performance exceeds expectations, customer will have been satisfied. Operational constraints related to customer location, the need to maintain customer satisfaction and the capabilities of the bank's main software are influential factors in motivating the decision to enter electronic banking services and consequently influencing the usage experience and thus affecting the level of satisfaction [8]. In a research among customers in Ghana $100 \%$ of respondents acclaimed SpeedBanking (an -e banking technology) as a faster way of depositing money, saving time and convenient way of depositing money. For $93 \%$ of respondents, SpeedBanking reduced the risk of attack by thieves and robbers, thereby creating a safer line of cash deposit, motivating the Bank of Ghana and the Ghana National Security in their bid to introduce cashless transactions in the country and reduce armed robbery respectively [9]. A study on electronic banking early 2019 indicates that this mode of service delivery was introduced in commercial banks in Uganda as early as 1997, however, adoption by customers is only at 39\% [10].

In its published terms and conditions for electronic banking, Stanbic Bank Uganda Limited Uganda Limited defines it to be all of the Bank's electronic banking services including internet Banking, mobile banking (WAP and USSD), the mobile banking application and any updates thereto. It promises to make every effort to ensure that its electronic banking services will be continuously available to the customer with a disclaimer, that is, the availability will be dependent on factors beyond their control, including the customer's such as mobile and internet network's availability, performance of their handsets, compatibility with the service and sufficient airtime being available to the customer. Should services not be available due to a factor beyond the bank's control, then it would not be held liable for the un-availability of the services [11]. Business models for providing online banking facilities to its customers are mainly two, the "bricks and clicks" and the direct bank or virtual bank or electronic primary bank. The former (also referred to as the incumbent bank) model applies online banking as an enhancement to its traditional banking sector. It integrates physical branches, ATMs, call centres and online service into a whole system and using e-banking as a new channel of delivering services. The later (also referred to as the direct bank or electronic primary bank) model involves no branch offices, instead it uses electronics, telecommunication network and wireless networking to provide banking services [12]. The wave for adoption of Information and Communication Technology as a competitive strategy has not spared economies and countries, whether developed or not [13]. 


\subsection{E-Transaction Monitoring}

Effective monitoring may necessitate the automation of certain parts of the monitoring process. The appropriate degree of automation will vary from institution to institution and is dependent on the scale, nature and complexity of the bank's business. Rules-based automated monitoring systems are capable of identifying unusual activities based on a set of parameters determined by the bank. These rules can be customised over time with regard to changes in the bank's business and the latest money laundering and terrorist financing methods. More sophisticated systems make use of neural networks and other intelligent technology to continually update customer profiles based on past transactions. They can identify transaction patterns between accounts, compare transaction activity with established money laundering and terrorist financing methods, and score transactions in terms of the degree of suspiciousness. A bank should have regard to its risk exposure to money laundering and terrorist financing activities and should consider the relevance and applicability to its business when selecting such systems. It is important to note that an automated transaction monitoring system can supplement but not replace human awareness in detecting unusual or suspicious activities.

\subsection{Theoretical Review}

\subsubsection{Theory of Reasoned Action (TRA)}

The theory of reasoned action resulted from the efforts of Martin Fishbein and Icek Ajzen in 1967. According to the theory a person's intention to perform a behaviour is the main predictor of whether or not they actually perform that behaviour. Strong intention leads to increased possibility to perform. It tallies very much with marketing models of consumer behaviour such as AIDA (Attract Interest Decide
Act) which have for long been used to explain consumer buying behaviour and is a useful guide in the adoption of marketing strategies including e-marketing, and by implication e-banking.

\subsubsection{Theory of Planned Behaviour}

The theory, according to which attitude toward behaviour, subjective norms, and perceived behavioural control are the factors which shape an individual's behavioural intentions and behaviours was proposed by Icek Ajzen in response to the shortcomings identified in the theory of reasoned action, especially the aspect of behavioural intention, which was much criticised. People are highly motivated when they know or believe when they feel that they can enact certain behaviours successfully than when they believe that they have less chances. In particular new dimensions introduced by Ajzen were the concept of "perceived behavioural control" (which refers to the degree to which a person believes they can control any given behavioural trend. Others are the concept of self-efficacy and controllability. Self-efficacy defines the level of effort required (or degree of difficulty encountered) when performing a behaviour. Controllability emphasises or refers to exogenous factors which impact on performance of the behaviour. When a person believes the factors are overwhelming, they will be discouraged but if the person has high perception and confidence of themselves, then they have an increased confidence that they are capable of performing the specific behaviour successfully. In relation to e-banking customers are highly motivated by easily navigable websites, augmented by high security as well as instructions that are not cumbersome. These generate confidence in the customers to the effect that they will be successful as they interface with the bank in their transactions. Its principles are much used in public relations, advertising and social as well as political campaign.

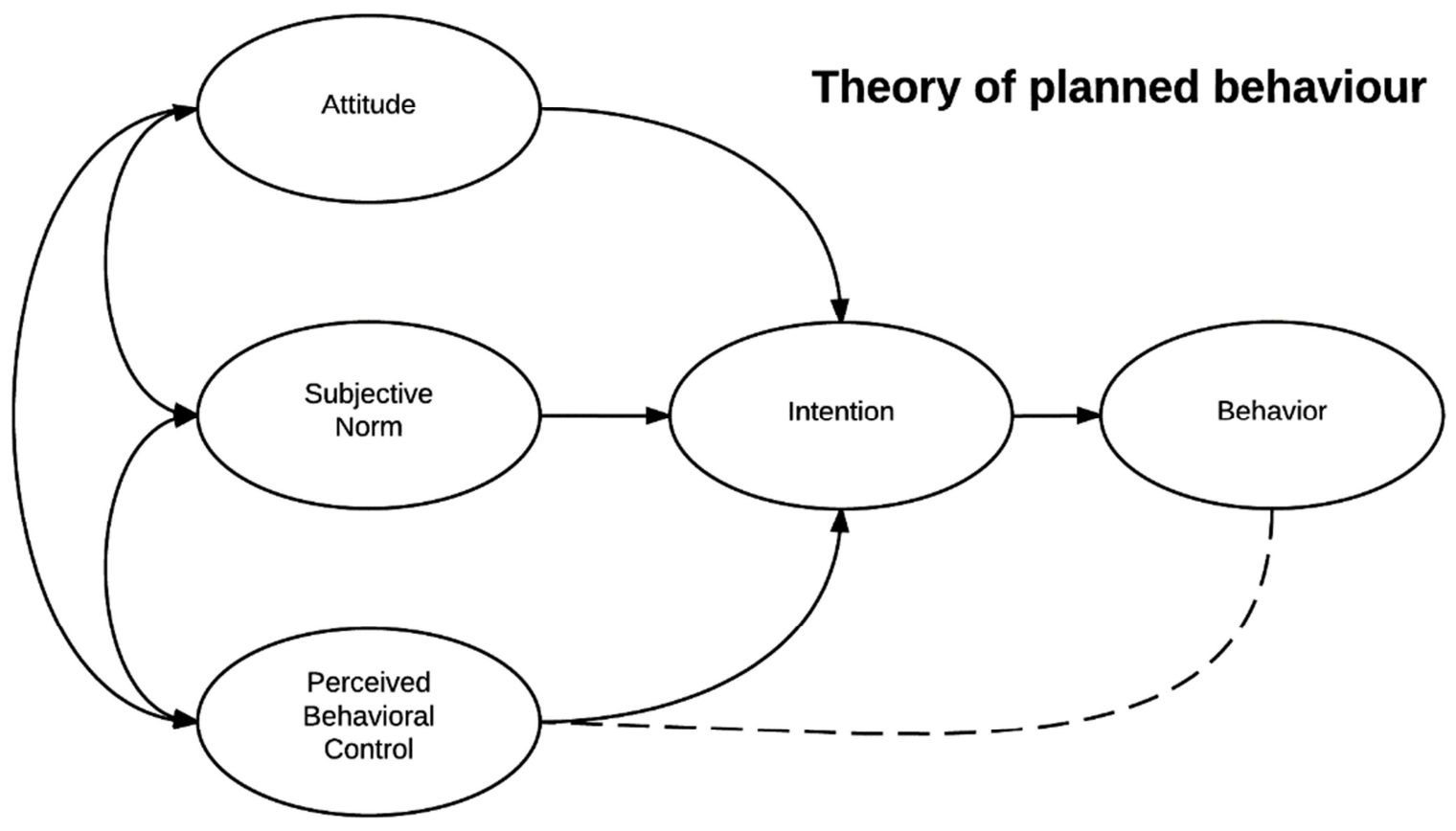

Figure 1. Theory of planned behaviour [14]. 
Figure 1 above illustrates the theory of planned behaviour is supposed to operate. Eventual behaviour is initially shaped by the attitude, subjective norms and perceived behavioural control of the decision maker. These in turn inform the intention of the decision maker.

\subsubsection{Innovation Diffusion Theory}

The Innovation Diffusion Theory explains people's aim to adopt innovations as a methodology to perform a customary action and advance. The stages through which a mechanical advancement passes, namely: information (presentation to its presence, and comprehension of its capacities); influence (the shaping of a good state of mind to it); choice (duty to its selection); execution (putting it to utilize); and affirmation (support taking into account positive results from it). The basic elements that focus the appropriation of advancement at the general level are the accompanying: relative favourable position, similarity, complexity, trial ability and perceptibility. The theory is concerned with the way in which another innovative thought, antique or procedure, or another. like for all achievements in human technological development is imparted through specific channels, after some time, among the individuals from a social framework. [15]

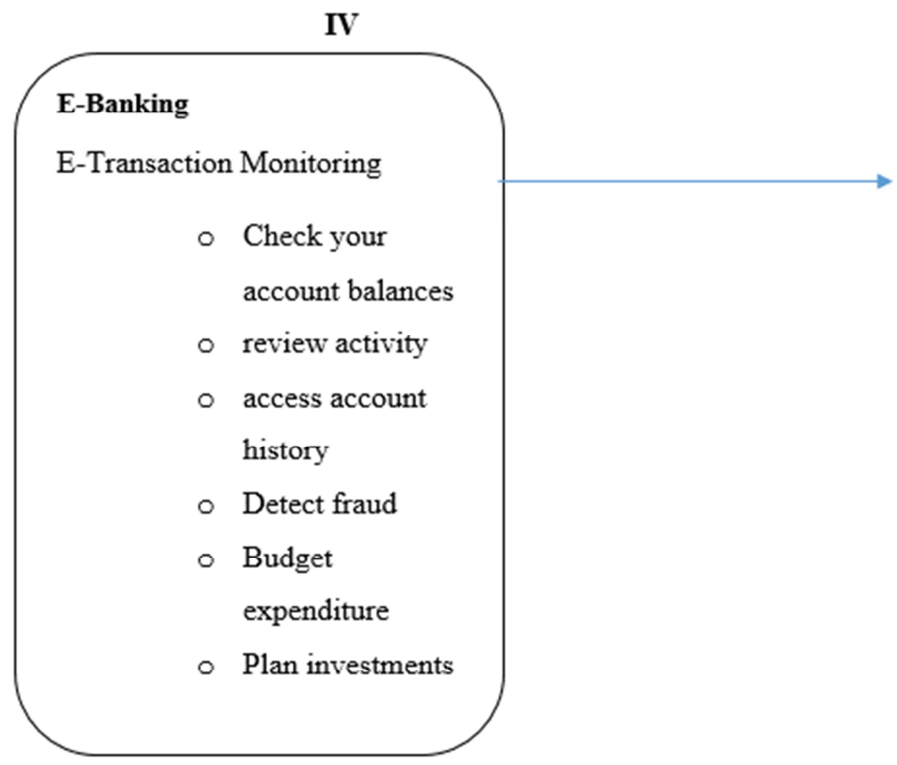

\subsection{Conceptual Framework}

A conceptual framework is a structure which the researcher believes can best explain the natural progression of the phenomenon to be studied [16]. It is arranged in a logical structure to provide a picture or visual display of how ideas in a study relate to one another and it assists the researcher in identifying and constructing his/her worldview on the phenomenon to be investigated [17]. It relates the independent variable (IV) with the dependent variable (DV) For example, the relationship between the dependent variable (customer satisfaction) and the independent variable (Ebanking) is a symmetrical relationship where by a change in the later is followed by the former [18].

In figure 2 below, e-transaction monitoring (the independent variable) enables the customer to, among others, check their account balances, review activity, access account history, detect fraud and to budget expenditure, plan investments with more ease and convenience than would be the case in traditional banking. The result is a satisfied customer, who spreads that feeling by word of mouth or word of mouse and reflected in increased loyalty to the bank and more customers.

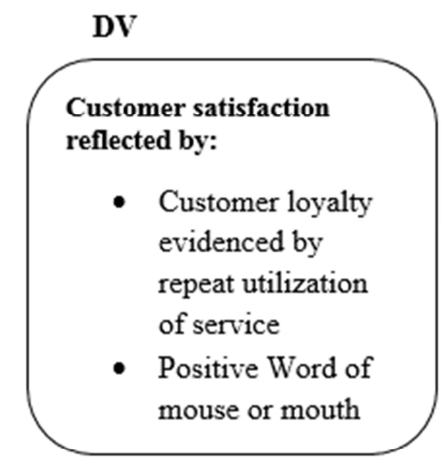

Figure 2. Conceptual Framework of the Study.

\subsection{Justification of the Study}

Indeed, there are few studies that have been carried out on electronic banking and customer satisfaction in Uganda, and none appears to have been carried out to ascertain the relationship between electronic monitoring and customer satisfaction in commercial banks. The specific Objective of the study therefore was to examine the effect of e-transaction monitoring on customer satisfaction. The hypothesis was to establish whether there is a positive relationship between etransaction monitoring on customer satisfaction in Stanbic Bank.

\section{Methodology}

Research methodology are the specific procedures or techniques used to identify, select, process, and analyse information about a topic. Basically, the section must answer at least two question, which are, how was the data collected or generated and how it was analysed [19].

\subsection{Research Design}

This investigation was based on a case study of Stanbic 
Bank Uganda Limited Uganda Limited, at its Head office in Kampala Capital City Authority. A cross-sectional approach, involving collecting data at once from employees and customers was adopted. The design was chosen due to limited time and financial resources to conduct a longitudinal study. The survey used both quantitative and qualitative research approaches. The former involved generating quantitative data using questionnaires and analysing it using numbers, while the latter involved generating qualitative data through interviews and analysing it using words.

\subsection{Study Population}

The target population of this study comprised of employees and customers in Uganda's commercial banking sector. However, the accessible population comprised of employees the bank and customers at the head office. According to the Head of Human Resources, Head office on Crested Towers was the biggest branch of Stanbic Bank Uganda Limited with over 110 employees.

\subsection{Determination of Sample Size}

A sample of 91 employees participated in this study. This sample size was determined using the table of appropriate sample size for a given population size [20].

Table 1. Showing the sample size of the respondents.

\begin{tabular}{lll}
\hline & Target population & Sample size \\
\hline Managers & 5 & 5 \\
Middle Level staff & 10 & 10 \\
E-banking operative staff & 5 & 5 \\
Customer relationship officers & 8 & 8 \\
Customers of Stanbic Bank. & 75 & 63 \\
Total & 103 & 91 \\
\hline
\end{tabular}

The study involved 5 managers, 10 Middle Level staff involved in E-banking operations, 5 Head office (Stanbic) Ebanking operative staff, 8 Customer relationship officers attending walk-in-customers and 63 Customers of Stanbic Bank.

\subsection{Sampling Techniques and Procedures}

Both probability and non-probability sampling techniques were employed in the study. The probability technique of proportional stratified random sampling was used in selecting employees to participate in the study. Proportional stratified random sampling involves dividing the population into mutually exclusive and exhaustive strata, and then selecting a random sample of subjects which is proportional to size of a given stratum [21]. In the case of this study, employees were grouped into 5 strata based on their respective work responsibilities and a sample of employees was drawn from each department, which was proportional to the number of employees in each department. The technique was preferred because the number of employees varied across the bank departments; therefore, it was used to ensure fair representation of employees from the respective departments in the sample.

The non-probability technique of purposive sampling was also used in selecting the 5 Managers of the departments that participated in the study. These individuals were chosen because they were assumed to be highly knowledgeable about issues of E-banking and customer satisfaction in the bank; and therefore, their opinions are important for purposes of comparison with employees' views.

\subsection{Data Collection Methods}

The questionnaire method of data collection was used. Questionnaire survey involved collecting quantitative data from selected employees in Stanbic Bank Uganda Limited in Kampala Capital City. The researcher took a written permission to collect data from employees and customers of Stanbic Bank Uganda Limited at the head office. Upon acceptance, the researcher then employed a combination of data collection methods including questionnaire survey, key informant interviews, and documentary review.

\subsection{Data Collection Instruments}

The study employed two research instruments a questionnaire and an interview guide. A questionnaire is a research instrument consisting of a series of questions to which respondents are expected to react to, usually in writing [22]. An interview guide is a method of collecting information through oral or verbal communication between the researcher and the respondents. Questionnaires are easy to administer; they make it relatively quick to collect information and quite cheap compared to other methods. The questionnaire comprised of sections on respondents' demographic characteristics, entrepreneurial education, prior entrepreneurial experience, entrepreneurial orientation and business success. The major study variables were measured using structured close-ended items adopted from previous research studies and assessed using a five-point Likert scale ranging from $1=$ strongly disagree to $5=$ strongly agree. Closeended questions were also used because they were easier to administer since each item followed specific alternative answers from which to choose.

\subsection{Pre-testing (Validity and Reliability)}

Validity refers to the extent to which an instrument is able to measure what it is supposed to measure [23]. To ensure validity of the instruments the following measures were undertaken. First, items in the instrument were largely adopted from past studies with validated research instrument, and where necessary, some were modified to suit the current study. Secondly, the instruments were taken for a pilot test before being administered to ensure that the items therein were clearly understood by the respondents and that they elicit the right responses. Reliability of instruments refers to the extent of accuracy or precision of a measuring instrument The reliability of the questionnaire was established through calculating the Cronbach Alpha value for all items considered in the questionnaire. The Cronbach's Alpha is calculated using the following formula [24]: 


$$
\alpha=\frac{k}{k-1}\left(1-\frac{\sum \sigma_{k}^{2}}{\sigma^{2}}\right)
$$

Where $\sum \sigma_{k}^{2}$ is the sum of variances of the $k$ parts (usually items) of the test.

$\sigma$ is the standard deviation of the test

\subsection{Procedure of Data Collection}

Employees were given questionnaires and requested to fill them within a specified time period, and were collected from the respondents upon completion. This method was used because it was quick, it was less time consuming and could adequately cover the entire sample within the proposed time frame [25]. Key informant interviews involved collecting qualitative data through in-depth face-to-face engagements with selected heads of department of Stanbic Bank Uganda Limited departments in the bank to compliment data obtained through questionnaire surveys.

\subsection{Data Analysis}

A combination of quantitative and qualitative data analysis techniques was employed in this study. Quantitative data analysis techniques involved the use of descriptive statistics such as frequencies and percentages to summarize responses on issues of E-banking and customer satisfaction while the Pearson's correlation coefficient was used to establish the relationship between dimensions of E-banking and customer satisfaction as specified in the study objectives. The qualitative data obtained through interviewing key informants were analysed using three recommended steps: (i) themes were identified in the data, (ii) redundant information deemed to lack a direct or indirect bearing on the themes was eliminated, (iii) themes were classified into major categories, and major categories were clustered into sub-categories with their concrete meaning being transformed into the research terms [26]. During and after the data collection process, great care was taken to ensure that data was properly cleaned, edited, coded and stored before further analysis. Cleaning and editing data involved eliminating the undesired data and ensuring consistency and appropriateness of responses, while coding data involved transforming responses into numerical form for quantitative analysis and creating code categories for qualitative data. The purpose of this was to enhance quality of data used for analysis purposes. The data was then entered into a Microsoft Office Excel computer program and analysed using the Statistical Package for Social Scientists (SPSS Version 18.0).

\section{Findings}

\subsection{Analysis of Objective Effect of E-monitoring on Customer Satisfaction}

In this section, we present the findings on the factors which constitute e-banking functionality in Stanbic Bank Uganda Limited. (Based on the 1-strongly disagree to 5-strongly agree scale rate). The results were backed by information from the open ended questions of the questionnaire.

Table 2. Employee Views on E-monitoring.

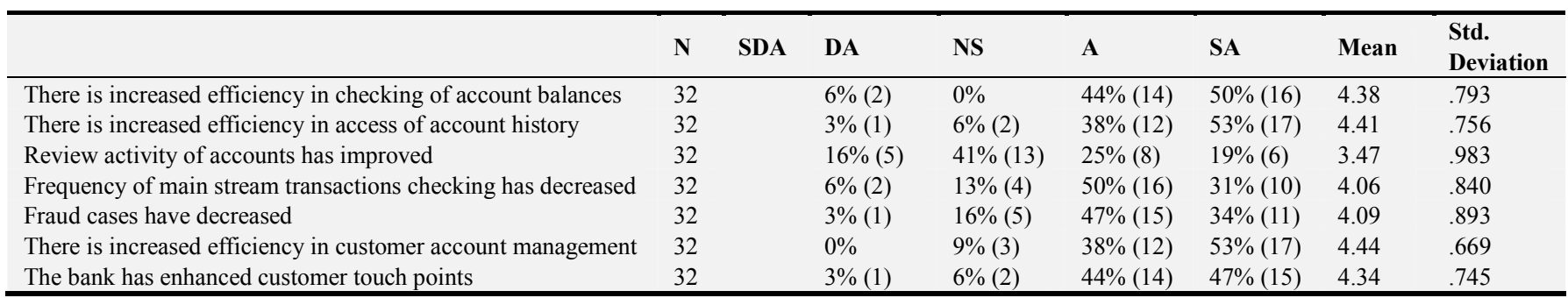

Key: $\mathrm{SD}=$ strongly disagree, $\mathrm{D}=$ Disagree, $\mathrm{NS}=$ Not sure, $\mathrm{A}=$ Agree, $\mathrm{SA}=$ strongly agree

From the table 2 above, the respondents were asked whether there is increased efficiency in checking of account balances. The results from the study revealed that, of the total respondents, $50 \%$ strongly agreed, while $44 \%$ agreed, $0 \%$ were neutral, while $6 \%$ disagreed and $0 \%$ strongly disagreed. This implies that the majority, $94 \%$ of the respondents were in agreement as shown by the statistics, $6 \%$ disagreed and $0 \%$ had a Neutral opinion with a mean of 4.38 and SD of 0.793 . The above statistics implied that with $94 \%$ in agreement in comparison to the $0 \%$ who disagreed this is a factor which should be upheld by the bank management. These findings show that the bank stakeholders should uphold efficiency in checking of account balances.

In order to find out whether, there is increased efficiency in access to account history; respondents were asked to state the extent to which they agreed with the above. Of the total respondents, 53\% strongly agreed, while 38\% agreed, $6 \%$ were neutral, while $5 \%$ disagreed and $0 \%$ strongly disagreed. This implies that the majority, $91 \%$ of the respondents were in approval, with a mean of 4.41 and SD of 0.756 . From the statistics above with $91 \%$ in agreement this is an aspect to be upheld by the bank officials in comparison to the $9 \%$ who were in disagreement. From the findings above this shows that to deliver on e-banking functionality this aspect should be upheld by the stakeholders. From the findings of the study the respondents were asked about Review activity of accounts has improved. Of the total respondents, $19 \%$ strongly agreed, while $25 \%$ agreed, $41 \%$ were neutral, while $16 \%$ disagreed and $0 \%$ strongly disagreed. This implies that the majority, $44 \%$ of the respondents were in approval with a 
mean of 3.47 and SD of 0.983 from the statistics above, this shows that this is a key attribute which should be addressed by the bank stakeholders in improving e-banking functionality. The respondents were asked about Frequency of main stream transactions checking has decreased. The results from the study revealed that, of the total respondents, $31 \%$ strongly agreed, while $50 \%$ agreed, $13 \%$ were neutral, while $6 \%$ disagreed and $0 \%$ strongly disagreed. This implies that the majority, $81 \%$ of the respondents were in agreement as shown by the statistics, with a mean of 4.06 and SD of 0.840. The different statistics implied that this is a good aspect to be upheld by the bank stakeholders in Stanbic bank.

In determining whether the Fraud cases have decreased, the study revealed that; of the total respondents, $34 \%$ strongly agreed, while $47 \%$ agreed, and $16 \%$ were neutral, while $3 \%$ disagreed and $0 \%$ strongly disagreed. This implies that the majority, $81 \%$ of the respondents were in agreement with a mean of 4.09 and SD of 0.893 . From the findings above this shows Fraud cases have decreased should be addressed by the bank stakeholders in Stanbic bank.

In order to find out whether, there is increased efficiency in customer account management respondents were asked to state the extent to which they agreed with the above. Of the total respondents, $53 \%$ strongly agreed, while $38 \%$ agreed, 9\% were neutral, while $0 \%$ disagreed and $0 \%$ strongly disagreed. This implies that the majority, $91 \%$ of the respondents were in approval, with a mean of 4.44 and $\mathrm{SD}$ of 0.699 . From the statistics above with $91 \%$ in agreement this is a positive aspect to the bank officials in comparison to the $0 \%$ who were in disagreement. From the findings above this shows that to deliver on the e-banking functionality this concern should be upheld.

In order to find out whether, the bank has enhanced customer touch points; respondents were asked to state the extent to which they agreed with the above. Of the total respondents, $47 \%$ strongly agreed, while $44 \%$ agreed, $6 \%$ were neutral, while $3 \%$ disagreed and $0 \%$ strongly disagreed. This implies that the majority, $91 \%$ of the respondents were in approval, with a mean of 4.34 and SD of 0.745 . From the statistics above with $91 \%$ in agreement this is a positive aspect to the bank officials in comparison to the $0 \%$ who were in disagreement. From the findings above this shows that to deliver on the e-banking functionality this concern should be upheld.

\subsection{Customer Views on E-monitoring}

Table 3. Customer views on E-monitoring.

\begin{tabular}{|c|c|c|c|c|c|c|c|c|c|}
\hline & $\mathbf{N}$ & Missing & SDA & DA & NS & $\mathbf{A}$ & SA & Mean & $\begin{array}{l}\text { Std. } \\
\text { Deviation }\end{array}$ \\
\hline Quick checking of account balances & 50 & 0 & $2 \%(1)$ & $4 \%(2)$ & $0 \%$ & $68 \%(34)$ & $26 \%(13)$ & 4.12 & .773 \\
\hline Easy access of account history & 50 & 0 & $2 \%(1)$ & $0 \%$ & $4 \%(2)$ & $62 \%(31)$ & $32 \%(16)$ & 4.22 & .708 \\
\hline Ever experienced fraud & 50 & 0 & $18 \%(9)$ & $36 \%(18)$ & $38 \%(19)$ & $6 \%(3)$ & $2 \%(1)$ & 2.38 & .923 \\
\hline Increased efficiency in account management & 49 & 1 & $0 \%$ & $2 \%(1)$ & $12 \%(6)$ & $63 \%(31)$ & $22 \%(11)$ & 4.06 & .659 \\
\hline Customer touch points are user friendly & 49 & 1 & $2 \%(1)$ & $2 \%(1)$ & $4 \%(2)$ & $57 \%(28)$ & $35 \%(17)$ & 4.20 & .790 \\
\hline
\end{tabular}

Key: $\mathrm{SD}=$ strongly disagree, $\mathrm{D}=$ Disagree, $\mathrm{NS}=$ Not sure, $\mathrm{A}=$ Agree, $\mathrm{SA}=$ strongly agree

From the table 3 above, the respondents were asked whether there is quick checking of account balances. The results from the study revealed that, of the total respondents, $26 \%$ strongly agreed, while $68 \%$ agreed, $0 \%$ were neutral, while $4 \%$ disagreed and $2 \%$ strongly disagreed. This implies that the majority, $94 \%$ of the respondents were in agreement as shown by the statistics, $6 \%$ disagreed and $0 \%$ had a Neutral opinion with a mean of 4.12 and SD of 0.773 . The above statistics implied that with $94 \%$ in agreement in comparison to the $0 \%$ who disagreed this is a factor which should be upheld by the bank management. These findings show that the bank stakeholders should uphold efficiency in checking of account balances.

In order to find out whether, there is easy access of account history; respondents were asked to state the extent to which they agreed with the above. Of the total respondents, $32 \%$ strongly agreed, while $62 \%$ agreed, $4 \%$ were neutral, while $0 \%$ disagreed and $2 \%$ strongly disagreed. This implies that the majority, $94 \%$ of the respondents were in approval, with a mean of 4.22 and SD of 0.708 . From the statistics above with $94 \%$ in agreement this is an aspect to be upheld by the bank officials in comparison to the $2 \%$ who were in disagreement. From the findings above this shows that to deliver on e-banking functionality this aspect should be upheld by the stakeholders.

From the findings of the study the respondents were asked about ever experienced fraud. Of the total respondents, $2 \%$ strongly agreed, while $6 \%$ agreed, $38 \%$ were neutral, while $36 \%$ disagreed and $18 \%$ strongly disagreed. This implies that the majority, $54 \%$ of the respondents were in disapproval with a mean of 2.38 and SD of 0.923 from the statistics above, this shows that this is a key attribute which should be addressed by the bank stakeholders in improving e-banking functionality.

The respondents were asked about increased efficiency in account management. The results from the study revealed that, of the total respondents, $22 \%$ strongly agreed, while $63 \%$ agreed, $12 \%$ were neutral, while $2 \%$ disagreed and $0 \%$ strongly disagreed. This implies that the majority, $86 \%$ of the respondents were in agreement as shown by the statistics, with a mean of 4.06 and SD of 0.659 . The different statistics implied that this is a good aspect to be upheld by the bank stakeholders in Stanbic bank.

In determining whether the customer touch points are user friendly, the study revealed that; of the total 
respondents, 35\% strongly agreed, while 57\% agreed, $4 \%$ were neutral, while $2 \%$ disagreed and $2 \%$ strongly disagreed. This implies that the majority, $92 \%$ of the respondents were in agreement with a mean of 4.20 and SD of 0.790 . From the findings above this shows customer touch points are user friendly should be upheld by the bank stakeholders in Stanbic bank. These findings show that stakeholders should uphold this aspect.

\subsection{The Relationship Between E-transaction Monitoring and Customer Satisfaction}

The researcher proceeded to statistically establish whether e-transaction monitoring positively influence customer satisfaction. This was guided by the following hypothesis: $e$ transaction monitoring positively influences customer satisfaction

\subsection{Correlation Analysis}

The hypothesis was preliminarily tested at a $95 \%$ level of significance (two-tailed) using Pearson's product-moment correlation coefficient, which measured the degree and direction of relationship between e-transaction monitoring and customer satisfaction; The results are presented in the table below.

Table 4. Correlation Matrix for E-transaction Monitoring and Customer Satisfaction.

\begin{tabular}{llll}
\hline Correlations & & & \\
\hline & & E-Transaction Monitoring & Customer satisfaction \\
\hline \multirow{3}{*}{ E-Transaction Monitoring } & Pearson Correlation & 1 & $.327^{* *}$ \\
& Sig. (2-tailed) & & .003 \\
& $\mathrm{~N}$ & 81 & 81 \\
& Pearson Correlation & $.327^{* *}$ & .003 \\
Customer satisfaction & Sig. (2-tailed) & 81 & 81 \\
\hline
\end{tabular}

**. Correlation is significant at the 0.01 level (2-tailed).

Table 4 shows that there is a weak positive relationship between e-transaction monitoring and customer satisfaction; $(\mathrm{r}=0.327 \mathrm{p}=0.003 \mathrm{n}=81)$. The relationship is statistically significant at $95 \%$ confidence level since p-value (Sig.) is less than $0.050(=0.000)$. This implies that improvements in e-transaction monitoring shall be related to improvements in customer satisfaction. Similarly decline in e-transaction monitoring shall be related to decline in customer satisfaction.

These findings from correlation analysis have established that e-transaction monitoring have a weak positive statistically significant relationship with customer satisfaction. Therefore, the hypothesis that was stated that "etransaction monitoring positively influences customer satisfaction" was accepted.

\subsection{Regression Analysis}

Regression analysis was used to establish the extent to which e-transaction monitoring affects customer satisfaction. The coefficient of determination (R Square) was used and the results are presented in the table below.

Table 5. Model Summary.

\begin{tabular}{|c|c|c|c|c|c|c|c|c|c|}
\hline \multirow{2}{*}{ Model } & \multirow{2}{*}{$\mathbf{R}$} & \multirow{2}{*}{ R Square } & \multirow{2}{*}{ Adjusted R Square } & \multirow{2}{*}{$\begin{array}{l}\text { Std. Error of the } \\
\text { Estimate }\end{array}$} & \multicolumn{5}{|l|}{ Change Statistics } \\
\hline & & & & & R Square Change & F Change & df1 & df2 & Sig. F Change \\
\hline 1 & $.327^{\mathrm{a}}$ & .107 & .095 & .58666 & .107 & 9.433 & 1 & 79 & .003 \\
\hline
\end{tabular}

a. Predictors: (Constant), e-transaction monitoring

Table 5 shows that the coefficient of determination (Adjusted R Square) is 0.095 . This implies that e-transaction monitoring accounts for $9.5 \%$ of the variance in customer satisfaction. There are therefore other factors outside etransaction monitoring that contribute to the greater percentage of customer satisfaction.

\subsection{Effects of E-transaction Monitoring on Customer Satisfaction}

Findings from descriptive statistics indicated that on average the respondents agreed that there are some etransaction factors that do affect customer satisfaction which include; quick checking of account balances, easy access of account history, increased efficiency in account management, customer touch points are user friendly. Further findings indicated that there was a weak statistically significant positive relationship between e-transaction and customer satisfaction.

\subsection{Examine the Effects of E-transaction Monitoring on Customer Satisfaction}

The study sought to examine the effect of e-transaction monitoring on customer satisfaction. The findings of the study revealed that e-transaction monitoring has a statistically significant relationship with customer satisfaction. The study findings are supported by other researches. It has been observed that, globally, information and communication technology services are the major driver of the changes occurring, and that the shift from traditional banking to electronic banking was an inevitable change 
necessitating considering leveraging technology to be a significant part of the bank's strategy in the provision of services with a competitive edge [27]. Increasingly intense competitiveness demands that firms implement a customerfocused strategy which raises the importance of customerrelated constructs such as customer satisfaction, most especially where the exchanges relationships are complex and customers are closely involved in the decision-making process, a key characteristic of the marketing mix of services provision (including banking) which emphasises process, people and minimal physical evidence. In such circumstances service quality and customer satisfaction are important antecedents of customer loyalty and customer satisfaction mediates the effects of service quality on customer loyalty [28]. In a study on Customers Satisfaction of Islamic Banks in Jordan, the researcher found that there is statistically significant impact of the electronic service quality (ease of use, web site design, privacy, and responsiveness). Most specifically with regard to the dimensions of reliability and effectiveness, the study indicates that they had insignificant impact on customers satisfaction [29].

\section{Conclusion}

The study has confirmed that e-transaction monitoring positively influences customer satisfaction" was accepted and that e-monitoring gives customers more control over their money. Unlike in conventional banking, e-banking customers are not bound by 'banking hours' and they do not have to physically go to the banking halls to be served. With e-monitoring customers can monitor their account (s) online any time, day or night and in great contrast with the case of the traditional monthly or quarterly "bank statements", bouncing a cheque (accidentally) is a thing of the past. This is possible through use of Software programs such as Microsoft Money or Quicken, which make reconciling an account easy and fast. E-monitoring enables quick checking of account balances, easy access of account history, increased efficiency in account management and it makes customer touch points are user friendly.

Effective monitoring necessitates the automation of certain parts of the monitoring process. The appropriate degree of automation will vary from institution to institution and is dependent on the scale, nature and complexity of the bank's business. Banks can identify transaction patterns between accounts, compare transaction activity with established money laundering and terrorist financing methods, as well as be able to monitor activities of hackers. Inevitably a bank that falls prey to hackers will have to recover through charging customers expensively or may indeed have to close shop. Such occurrences are detrimental not only to the investors or owners of the bank and customers, but also to the economy overall. It is important to note that an automated transaction monitoring system can supplement but not replace human awareness in detecting unusual or suspicious activities.

Further research is recommended on the likely negative externalities of the adoption of information and communication technology in the financial services sector.

\section{References}

[1] Saha Permita, Zhao Yanni (2006). Relationship between online service quality and customer satisfaction, a study in internet banking, master thesis, Lulea University of Technology.

[2] R. Manohar, (2016) Customer Satisfaction on Internet Banking Services with Reference to Virudhunagar District, Glacier Journal Of Scientific Research ISSN: 2349-8498.

[3] Hani A. AlHaliq \& Ahmad A. AlMuhirat (2016): Customer Satisfaction with Electronic Banking Services in the Saudi Banking Sector, Asian Social Science; Vol. 12, No. 5; 2016 ISSN 1911-2017 E-ISSN 1911-2025 Published by Canadian Centre of Science and Education.

[4] http://correctbanking.com/index.php)

[5] Radislav Jovovic, Elvis Lekic, Miroslav Jovovic (2016): Monitoring the Quality of Services in Electronic Banking, Journal of Central Banking Theory and Practice, 2016, 3, pp. 99-119.

[6] KPMG (2019): Global Banking Fraud Survey The multifaceted threat of fraud: Are banks up to the challenge?

[7] Emad Abu-Shana et al (2015): Security and Fraud Issues of Ebanking, International Journal of Computer Networks and Applications (IJCNA) Volume 2, Issue 4, July - August (2015).

[8] Boateng, R., and Molla, A. (2006). Developing E-banking Capabilities in a Ghanaian Bank: Preliminary Lessons, Journal of Internet Banking and Commerce, Vol. 11, No. 2.

[9] Kwame Owusu Kwateng et al (2013): Emerging trends of Electronic Banking in Ghana, Information and Knowledge Management www.iiste.orgISSN 2224-5758 (Paper) ISSN 2224-896X (Online) Vol. 3, No. 6, 2013.

[10] Eva Nannozi, Asiimwe Viola, Oroma Annabella Asedri (2019): Electronic Banking and Customer Satisfaction in the Uganda commercial banks https://www.ndejjeuniversity.ac.ug/electronic-banking-andcustomer-satisfaction-in-the-uganda-commercial-banks

[11] https://www.stanbicbank.co.ug

[12] Zheng Xianrongb, Xu Xiaoboc Yao Meifanga, Di He a, (2017): Impact of payment technology innovations on the traditional financial industry: A focus on China https://doi.org/10.1016/j.techfore.2017.12.023

[13] (Cheruiyot, 2013) Cheruiyot, S. K. (2010). Impact of internet banking on financial performance of commercial banks in Kenya. Unpublished MBA project. Nairobi: University of Nairobi.

[14] https://en.wikipedia.org/wiki/Theory_of_planned_behavior

[15] Rogers, E. M. (1995). Diffusion of Innovations. 4th ed., New York: The Free Press.

[16] Camp, W. G. (2001). Formulating and Evaluating Theoretical Frameworks for Career and Technical Education Research. Journal of Vocational Educational Research, 26 (1), 27-39. 
[17] Grant, C. \& Osanloo, A. (2014). Understanding, Selecting, and Integrating a Theoretical Framework in Dissertation Research: Creating the Blueprint for 'House'. Administrative Issues Journal: Connecting Education, Practice and Research, Pp. 12-22 DOI: 10.5929/2014.4.2.9.

[18] Philip Kotler (2017): some of my adventures in marketing, Journal of Historical Research in Marketing 9 (2).

[19] Patricia Shields, Hassan Jajali (2013): Intermediate theory: the missing link in successful Scholarship, Journal of Public Affairs Education.

[20] Amin, M. E. (2005) Social Science Research: Conception, Methodology and Analysis. Makerere University Press, Kampala.

[21] Krejcie, Robert V., Morgan, Daryle W (1970) "Determining Sample Size for Research Activities", Educational and Psychological Measurement, 1970.

[22] Sekaran, U. (2003). Research methods for business: A skill building approach, 4edn. New York: John Wiley and Sons Inc.

[23] Shuttleworth M. Internal Consistency Reliability. 2015. https:// explorable.com/internal-consistency-reliability.

[24] Bonett, D. G. (2010). "Varying coefficient meta-analytic methods for alpha reliability". Psychological Methods.
[25] Mugenda, O. M. \& Mugenda, A. G. (2003). Research methods: Quantitative and qualitative Approaches. Nairobi: African Centre for Technology Studies.

[26] John W. Creswell, Research Design: Qualitative, Quantitative, and Mixed Methods Approaches, Journal of Social and Administrative Sciences.

[27] Obeid AL-SHBIEL, Muhannad Akram AHMAD2 (2016): A Theoretical Discussion of Electronic Banking in Jordan by Integrating Technology Acceptance Model and Theory of Planned Behaviours, International Journal of Academic Research in Accounting, Finance and Management Sciences.

[28] Ngo Vu Minh, Nguyen Huan Huu (2016) The Relationship between Service Quality, Customer Satisfaction and Customer Loyalty: An Investigation in Vietnamese Retail Banking Sector Journal of Competitiveness id-Vol. 8, Issue 2, pp. 103 116, June 2016 ISSN 1804-171X.

[29] AL-HAWARY Warda Fares, AL-SMERAN (2017): Impact of Electronic Service Quality on Customers Satisfaction of Islamic Banks in Jordan Sulieman Ibrahim Shelash International Journal of Academic Research in Accounting, Finance and Management Sciences Vol. 7, No. 1, January 2017, pp. 170-188E-ISSN: 2225-8329, P-ISSN: 2308-0337. 